\title{
ESPAÇOS DE CONVERSAÇÃO: OS BLOGS E A CONSTRUÇÃO DA CIBERDEMOCRACIA NO BRASIL
}

\author{
CONVERSATION PLACES: THE BLOGS AND THE CYBERDEMOCRACY'S \\ CONSTRUCTION IN BRAZIL
}

\begin{abstract}
LETÍCIA BODANESE RODEGUERI
Acadêmica do Curso de Direito da Universidade Federal de Santa Maria (UFSM). Integrante dos Projetos de Pesquisa "Ativismo Digital e as novas mídias: desafios e oportunidades da cidadania global" e "(Des)controle da blogosfera: entre a regulação e a censura no ciberespaço". Pesquisadora bolsista do Programa FIPE Júnior/UFSM.
\end{abstract}

FRANCIELI PUNTEL RAMINELLI

Acadêmica do Curso de Direito da Universidade Federal de Santa Maria (UFSM). Integrante dos Projetos de Pesquisa "Ativismo Digital e as novas mídias: desafios e oportunidades da cidadania global" e "(Des)controle da blogosfera: entre a regulação e a censura no ciberespaço".

RafaEl SANTOS DE OLIVEIRA Doutor em Direito pela Universidade Federal de Santa Catarina (UFSC). Professor Adjunto I no Departamento de Direito da Universidade Federal de Santa Maria (UFSM). Coordenador dos projetos de pesquisa dos Projetos de Pesquisa "Ativismo Digital e as novas mídias: desafios e oportunidades da cidadania global" e "(Des)controle da blogosfera: entre a regulação e a censura no ciberespaço"

(CNPq).

\section{RESUMO}

No século XXI é visível o desenvolvimento das novas tecnologias de informação e comunicação (NTICs), em especial da Internet, pois a dinamicidade e rapidez do meio, bem como a transposição de barreiras temporais e territoriais, possibilitam o fomento de discussões sobre as possibilidades de participação mais efetiva da população na construção da democracia contemporânea. A blogosfera surge como um local alternativo à efetivação do debate da temática, porque possibilita a publicação instantânea em rede, deixando ao próprio cibernauta a escolha do conteúdo e da abordagem realizada. 0 presente artigo objetiva discutir se os espaços de conversação proporcionados pelos blogs estão sendo utilizados com a finalidade de auxiliar na construção da ciberdemocracia no Brasil. Para tanto, utilizou-se dos métodos bibliográfico e documental, baseando-se o estudo em análise sistemática e não participativa em blogs, bem como no ranking dos 20 blogs mais acessados no Brasil, no ano de 2011. Concluiu-se da análise do referido ranking que embora exista uma gama de espaços online à disposição da população, essa não se utiliza da blogosfera com objetivos de discutir temáticas relativas ao exercício da democracia no Brasil, limitando-se a tratar de questões de lazer, moda e entretenimento.

Palavras-chave: Ativismo digital; ciberdemocracia; web 2.0; blogosfera.

\begin{abstract}
The development of new information and communication technologies (NICTs), especially the Internet, is visible in the twenty-first century, because the dynamicity and the speed of this media, as well the transposition of temporal and spatial barriers, allows the promotion of discussions about the possibilities of more effective participation of the population in the construction of the contemporary democracy. The blogosphere emerges as an alternative place to the realization of the debate about democracy, because it enables instant publishing network, allowing internet users the choice the content to be published and the approach taken. The present article discusses if the spaces provided by conversational blogs are being used for the purpose of assisting in the construction of cyberdemocracy in Brazil. The research was based in the bibliography and documental methods, and also in the systematic and non-participative analysis in blogs, as well in the ranking of the 20 most visited blogs in Brazil, in 2011. The conclusion, based in the ranking, is that while there is a range of spaces online available to the internet users, people don't use the blogosphere for purposes to discuss issues relating to the exercise of democracy in Brazil, limited to addressing issues of leisure, fashion and entertainment.
\end{abstract}

Keywords: Digital activism; cyberdemocracy; web 2.0; blogosphere.

Resultados parciais do Projeto de Pesquisa “(Des)controle da blogosfera: entre a regulação e a censura no ciberespaço", desenvolvido no Curso de Direito da UFSM e contemplado com recursos do Edital MCTI/CNPq/MEC/CAPES nº 07/2011.

REDESG / Revista Direitos Emergentes na Sociedade Global - www.ufsm.br/redesg v. 1, n. 1, jan.jun/2012 


\section{SUMÁRIO}

INTRODUÇAO; 1 A CIBERDEMOCRACIA E A POLÍTICA EM TEMPOS DE WEB 2.0; 2 A CONSTRUÇÃO DA PARTICIPAÇÃO DEMOCRÁTICA EM BLOGS; 3 A UTILIZAÇÃO DOS BLOGS NO BRASIL: RANKING DOS 20 BLOGS MAIS ACESSADOS NO ANO DE 2011; CONCLUSÃO; REFERÊNCIAS.

\section{INTRODUÇÃO}

A Internet constitui-se em um novo ponto de encontro - virtual - que possibilita facilitar a relação entre as pessoas, as quais podem encontrar-se a qualquer momento, independente de barreiras físicas ou temporais. 0 advento da Internet e a consequente popularização de seu uso proporcionaram à população considerável participação em assuntos cotidianamente tratados pela mídia tradicional, a exemplo das questões políticas e legislativas. A mobilidade, facilidade de acesso e rapidez com que as informações são transmitidas permitem que uma pessoa com computador, celular ou Ipad, conectados à rede, propague informações de forma instantânea.

Se, inicialmente, as pessoas utilizavam a Internet somente para encontrar amigos e cultivar sua rede social, ou ainda para encontrar informações sobre determinado assunto, esse panorama vem se modificando. Com a adoção do conceito de web 2.0, é possível a participação coletiva na própria construção da Internet, pois as pessoas encontraram outros motivos e formas de utilizá-la, podendo livremente expressar-se e também criar informações. Já não é mais suficiente manter-se em contato somente com as pequenas redes sociais, para fins particulares, pois existem movimentos, manifestações, discussões e a oportunidade de "falar", ou melhor, digitar as ideias, em uma constante troca de informações que oportunizam o desenvolvimento de uma comunidade global, interconectada e sensível às questões em comum.

A Internet configura-se como um espaço de possibilidades, com o crescimento da participação popular e da interação social, cujos efeitos políticos e jurídicos são cada vez mais evidentes e influentes. Com isto, a participação e a abertura da sociedade para as questões políticas vêm sofrendo grandes transformações, as quais provavelmente crescerão nos próximos anos.

A blogosfera surge como novo mecanismo desta articulação democrática na Internet, pois possui um diferencial significativo em relação às mídias tradicionais (televisão, rádio, jornal), uma vez que aumenta a interação entre internautas através da possibilidade da inserção 
ISSN 2316-3054

de comentários e posts nos blogs, bem como da livre emissão de conteúdo, sem a realização de uma censura prévia, como ocorre nos meios de comunicação tradicionais.

Diante disso, surge uma problemática central: o exercício da ciberdemocracia em blogs é possível? O debate público promovido pelos internautas na blogosfera contribui para uma participação democrática e efetiva dos cidadãos?

A análise da blogosfera como um meio de participação popular na construção de uma ciberdemocracia é essencial neste contexto de ampliação ao acesso à Internet. Estando ela presente no cotidiano de bilhões de pessoas, resta em destaque o papel exercido por instrumentos como os blogs, de fácil acesso popular, bem como suas possibilidades de influência em ações políticas.

Para desenvolver o estudo, foram empregados os métodos bibliográfico e documental, bem como análise sistemática e não participativa em blogs, demonstrando que as características de tais ferramentas permitem grande interação entre os cibernautas. Ainda, analisou-se a lista dos 20 blogs mais acessados no ano de 2011 pelos brasileiros, com a finalidade de verificar quais são os principais assuntos debatidos pelos internautas nos blogs.

O trabalho foi dividido em três tópicos, a saber: na primeira parte foi analisada a construção da ciberdemocracia no ambiente virtual, através do desenvolvimento das características da Internet até o advento da web 2.0. Após, foi abordada a participação democrática em blogs, por meio da possibilidade de interação e instantaneidade das publicações que esta ferramenta apresenta; e, no último tópico do artigo, foi analisado como os blogs vêm sendo utilizados pelos brasileiros na prática, através do exame do ranking dos blogs mais acessados no ano de 2011.

\section{A CIBERDEMOCRACIA E A POLÍTICA EM TEMPOS DE WEB 2.0}

No século XXI, não é difícil observar a inserção da Internet no cotidiano das pessoas. Ao longo dos últimos vinte anos, essa participação tomou um grande espaço, sendo que, atualmente, na maioria dos países industrializados, aproximadamente $80 \%$ da população está conectada à Internet, em suas próprias casas ${ }^{1}$. Esta porcentagem de "acessos" aumenta se considerarmos outras "fontes" que regularmente oferecem conexões, como, por exemplo, o

\footnotetext{
${ }^{1}$ LEMOS, André; LÉVY, Pierre. 0 futuro da internet: em direção a uma ciberdemocracia. 2. ed. São Paulo: Paulus, 2010. p.10.

REDESG / Revista Direitos Emergentes na Sociedade Global - www.ufsm.br/redesg v. 1, n. 1, jan.jun/2012
} 
ISSN 2316-3054

local de trabalho ou estudo, ou as escolas e universidades. Além disso, a opção de acesso em locais públicos (restaurantes, clubes, shoppings, entre outros) também é crescente, existindo até mesmo praças a céu aberto que oferecem acesso à Internet sem fio, gratuitamente.

Além do aumento do acesso à Internet, em termos gerais, outro dado deve ser analisado. Se por um lado este aumento poderia ocorrer somente em sites fechados, sem interatividade ou trocas entre os internautas, com o chamado tipo top-down (de cima para baixo), a realidade aponta avanço da participação popular na Internet. Ao invés das páginas "fechadas", nas quais as informações postas estão prontas, tem-se percebido o crescimento da utilização das páginas construídas por usuários, utilizadas como forma de troca e construção de ideias, defesa de direitos e encontro de minorias. Não somente a Internet insere-se no cotidiano das pessoas, mas também as pessoas se inserem nela, pois:

[...] a mídia atual tanto constitui a principal fonte de informação para a maioria da população, a partir da qual forma sua opinião política, quanto é um instrumento de organização e participação em protestos ou movimentos de participação cívica².

Desta forma, tem-se a perspectiva bottom-up, na qual as ideias emanam de baixo para cima, através da construção dos internautas. Esta nova fórmula traz a interatividade, principal benefício oferecido pela Internet em relação a outras mídias, como, por exemplo, os tradicionais jornal impresso e televisão. Conforme explica Cardoso ${ }^{3}$, as informações encontradas na Internet, menosprezadas pelas mídias tradicionais no passado, tornaram-se amplamente aceitas, o que proporcionou o funcionamento da Internet igualmente como um meio de comunicação de massa, modificando os temas e discursos dominantes em outras mídias ${ }^{4}$. Ao permitir maior liberdade para a publicação de notícias e discursos, a Internet forçosamente modificou também as mídias tradicionais, as quais, na grande maioria dos casos, mantinham “em pauta” assuntos de seu interesse.

Não se pode negar que a televisão mantém a preferência da maior parte da população. Entretanto,

\footnotetext{
${ }^{2}$ CARDOSO, Gustavo. A mídia na sociedade em rede: filtros, vitrines, notícias. Rio de Janeiro: FGV, 2007. p. 326.

${ }^{3}$ Gustavo Cardoso é docente no Departamento de Ciências e Tecnologias de Informação do ISCTE em Lisboa, Portugal. Lecciona nas em diversas licenciaturas do ISCTE, nos Mestrados de Comunicação, Cultura e Tecnologias de Informação e Bibliotecas Digitais e na Pós-Graduação de Jornalismo ISCTE/ESCS.

${ }^{4}$ Ibidem, p. 326.
}

REDESG / Revista Direitos Emergentes na Sociedade Global - www.ufsm.br/redesg v. 1, n. 1, jan.jun/2012 
[...] deve-se notar que as gerações que conviveram com a internet na sua infância e adolescência têm valorizações muito mais baixas do interesse conferido à televisão do que aquelas que apenas conviveram com a informatização em fases mais avançadas da idade adulta (41, $2 \%$ vs. $80,4 \%)^{5}$.

$\mathrm{Na}$ referida pesquisa, Cardoso analisou a população portuguesa, em suas diferentes faixas etárias, diante das mídias existentes. Apesar de específicos de Portugal, os resultados refletem dados mundiais, como o aumento da utilização da Internet, a “desvalorização" da televisão pelos mais jovens e o multitasking, ou seja, a utilização simultânea de diferentes tecnologias (como por exemplo, ver televisão enquanto acessa a Internet) ${ }^{6}$.

Resta comprovada a grande inserção da Internet no cotidiano das pessoas, com a importante ressalva de que esta não é somente utilizada para obter informações, como também para criá-las. E, através desta possibilidade, o internauta descobriu que também pode utilizá-la na construção cidadã de seu Estado, configurando uma ciberdemocracia, significa dizer, a Internet como "uma nova relação com o espaço e o tempo, de uma nova dimensão de vida na pólis"7.

A adoção desta postura ativista pelos cibernautas torna-se, na atualidade, essencial não somente para a organização de movimentos, mas principalmente para influenciar os demais cidadãos e provocá-los a emitirem as suas opiniões, construindo, assim, um debate público de forma online. Surge a chamada ciberdemocracia, democracia online ou democracia digital, a qual é entendida como uma nova forma de discussão de assuntos relacionados à política e democracia, porém no espaço virtual.

Pierre Lévy ${ }^{8}$ afirma que a novidade trazida pela Internet, qual seja, da mundialização da política, reside:

[...] mormente na possibilidade, para os movimentos de oposição ou as organizações activistas, de se organizarem e se coordenarem em tempo real à escala planetária [...]. A verdadeira inovação consiste na flexibilidade e na facilidade dos processos de coordenação. Já não é preciso organizar-se pesada, burocrática e hierarquicamente.

\footnotetext{
${ }_{6}^{5}$ Ibidem, p. 327.

${ }^{6}$ Ibidem, p. 347.

${ }^{7}$ LEMOS, André; LÉVY, Pierre. 0 futuro da internet: em direção a uma ciberdemocracia. 2. ed. São Paulo: Paulus, 2010. p. 29.

${ }^{8}$ LÉVY, Pierre. Ciberdemocracia. Lisboa: Instituto Piaget, 2003. p. 137.

REDESG / Revista Direitos Emergentes na Sociedade Global - www.ufsm.br/redesg v. 1, n. 1, jan.jun/2012
} 
ISSN 2316-3054

Dentro desse contexto, surgem duas vertentes: a dos ciberotimistas e os ciberpessimistas. Enquanto os ciberotimistas apostam todas suas fichas no papel desempenhado pela Internet, os ciberpessimistas, por sua vez, mantêm “um pé atrás”, com desconfiança e um pouco de ceticismo acerca dos benefícios que a Internet pode trazer. Questiona-se: configura a Internet, nos dias de hoje, um espaço privilegiado para o cidadão? E quanto a este cidadão, consegue visualizar o ciberespaço como uma oportunidade de expressão e luta por direitos/ideias? Para os ciberotimistas ${ }^{9}$ :

[...] as novas tecnologias de informação e comunicação possuem a capacidade de nos salvar das nossas tendências cívicas mais apáticas. Espera-se, assim, que a informação disponível na internet tenha a potencialidade de permitir ao público tornar-se mais conhecedor dos assuntos políticos, mais organizado na expressão dos seus pontos de vista por e-mail, grupos de discussão online, chats e mais ativo na mobilização em torno de assuntos das suas comunidades.

Os ciberotimistas acreditam na implantação de uma democracia digital através do uso consciente da Internet, uma vez que os cidadãos, nomeadamente os jovens nascidos na era digital, utilizarão as novas tecnologias para participar da vida política dentro e fora do ambiente virtual. Com isso, os novos cidadãos digitais passarão a utilizar as novas tecnologias informacionais, principalmente as redes sociais, para irradiar suas ideias e promover articulações em torno de causas sociais, como por exemplo, o uso de uma página do Facebook para divulgar campanhas anti-homofóbicas, ou então defender a causa dos animais.

Já os ciberpessimistas são mais céticos quanto ao uso das novas tecnologias da informação, pois afirmam que estes mecanismos não mudarão a participação políticodemocrática através da rede virtual, uma vez que o processo de mobilização passa pelas mídias tradicionais, que ainda estão sob o domínio de poucos.

Esta questão é suscitada principalmente porque grande parte das pessoas conhece e utiliza a rede somente para manter contatos e se expor, ou seja, entende a Internet somente por suas redes sociais. Redes sociais, de acordo com Raquel Recuero ${ }^{10}$,“[...] é gente, é interação, é troca social. É um grupo de pessoas, compreendido através de uma metáfora de estrutura, a estrutura de rede. Os nós da rede representam cada indivíduo e suas conexões, os

${ }^{9}$ CARDOSO, Gustavo. A mídia na sociedade em rede: filtros, vitrines, notícias. Rio de Janeiro: FGV, 2007. p. 375.

${ }^{10}$ Raquel Recuero é professora e pesquisadora do Programa de Pós-Graduação em Letras da Universidade Católica de Pelotas. É também pesquisadora vinculada ao CNPq. É doutora em Comunicação e Informação pela Universidade Federal do Rio Grande do Sul. Site: http://www.raquelrecuero.com.

REDESG / Revista Direitos Emergentes na Sociedade Global - www.ufsm.br/redesg v. 1, n. 1, jan.jun/2012 
ISSN 2316-3054

laços sociais que compõem os grupos"11. Como exemplo, citam-se os internacionalmente conhecidos Facebook, Orkut e Twitter, sites e blogs que oferecem este contato/exposição pública, mas que também, ainda que timidamente, também já participam de movimentos sociais, conforme acima exemplificado.

Inicialmente, as redes sociais oferecem a conexão entre os internautas. Superada essa fase, elas propiciam a difusão de informações destes grupos, os quais, já conectados, encontram seus "iguais" e possuem facilidade em comunicar-se. Este processo, em comparação a rede offline, na qual as notícias somente se espalham quando as pessoas se encontram, fisicamente, e conversam, torna mais fácil a discussão, compartilhamento, repasse e amplitude das ideias em comum, transpassando, inclusive, barreiras físicas. Desta forma, "essas redes proporcionaram mais voz às pessoas, mais construção de valores e maior potencial de espalhar informações. São, assim, essas teias de conexões que espalham informações, dão voz às pessoas, constroem valores diferentes e dão acesso a esse tipo de valor"12.

É notável o fato de que muitos as utilizam com o intuito de encontrar informações e explorar interesses além das fronteiras de seu círculo social, compartilhando ideias e conhecendo outras, muitas vezes oriundas de lugares antes inimagináveis, seja pela barreira física ou por outras restrições. De fato, com a rede conectada aos mais diversos países e pessoas, muitos evoluíram do status "formadores de opinião" para "formadores de diretrizes". Significa dizer que o papel adquirido por cidadãos comuns culmina em um resultado muito significativo: a influência em grandes questões políticas globais ${ }^{13}$. Este "movimento" configura a famosa terminologia “mídias sociais", também conhecida como "mídias digitais" ou "novas mídias".

As mídias sociais, em sua definição mais simplória, são os blogs, microblogs, wikis, redes sociais, comunicadores instantâneos, fóruns e outros instrumentos propiciados online para a troca de experiências, opiniões, ideias e planejamentos. Englobam outras ferramentas além das conhecidas redes sociais, e vêm sendo descobertas e muito utilizadas pelos internautas. Luli Radfahrer $^{14}$ afirma que “[...] elas se tornaram rapidamente as novas praças públicas. Graças a

\footnotetext{
${ }^{11}$ RECUERO, Raquel. Redes Sociais na Internet. Porto Alegre: Sulina, 2009. p. 25.

12 Ibidem, p. 25.

${ }^{13}$ GUZZI, Drica. Web e participação: a democracia no século XXI. São Paulo: Senac São Paulo, 2010.p. 28.

${ }^{14}$ Luli Radfahrer (luli.com.br) é Ph.D. em comunicação digital pela Escola de Comunicações e Artes da Universidade de São Paulo (ECA-USP), de onde também é professor há mais de quinze anos. Hoje desenvolve projetos de inovação, comunicação digital e design de interação para empresas no Brasil, Canadá, Estados Unidos e Oriente Médio.
}

REDESG / Revista Direitos Emergentes na Sociedade Global - www.ufsm.br/redesg v. 1, n. 1, jan.jun/2012 
ISSN 2316-3054

elas é possível se relacionar com muito mais pessoas que seria possível em qualquer ambiente físico"

Esta conexão interplanetária, na qual as questões internacionais são rapidamente compartilhadas e a Internet é vista como uma plataforma (onde qualquer construção é possível) possui uma nomenclatura especial: web 2.0. Criado em 2004 por Tim O’Reilly, o termo web 2.0 não possui um conceito rígido, sendo um conjunto de princípios e práticas que interligam sites em um sistema. Possui como "[...] parte essencial tirar partido da inteligência coletiva, transformando a web em uma espécie de cérebro global” ${ }^{16}$.

A web 2.0 apresenta como princípio-base utilizar-se da inteligência coletiva ${ }^{17}$ para construir melhores aplicativos, ou seja, através da participação dos usuários, que podem sugerir, avaliar e até mesmo criticar, a web 2.0 objetiva construir e reconstruir, sempre visando melhorar a rede através das ideias comuns. É neste contexto que surgem os já referidos sites bottom-up, nos quais através da participação popular e do relacionamento dos participantes pode-se utilizar soluções e conteúdos diversos para obter uma "experiência integrada" 18.

O resultado desta "liberdade" para compor sites e blogs e difundir ideias é o aumento na participação dos indivíduos, os quais sentem que na Internet podem fazer parte de discussões, opinar e “fazer mais para e por eles próprios”. Além disso, a organização e realização de atividades em grupos não estão limitadas a sistemas hierárquicos, como de praxe em empresas, por exemplo. Na Internet a hierarquia, se existe, é horizontal, sendo possível a todos, sem diferenças ou preferências, participar. Por fim, dentro destas condições, ocorre uma "melhoria da capacidade dos indivíduos fazerem mais em organizações formais que operam fora da esfera do mercado"19.

\footnotetext{
${ }^{15}$ RADFAHRER, Luli. In: SPYER, Juliano (Org). Para entender a internet: noções, práticas e desafios da comunicação em rede. 2009. Disponível em: <www.esalq.usp.br/biblioteca/PDF/Para_entender_a_ Internet.pdf>. Acesso em: 5 ago. 2012. p. 47.

${ }^{16}$ O’REILLY, Tim. 0 que é Web 2.0 - Padrões de design e modelos de negócios para a nova geração de software. Disponível em: <http://www.cipedya.com/doc/102010> Acesso em: 10 ago. 2012. p. 15.

17 De acordo com Pierre Levy, "[...] inteligência coletiva é uma inteligência difundida por toda parte, incessantemente valorizada, coordenada em tempo real, que resulta em uma mobilização efetiva das competências. Seus objetivos são o reconhecimento e o enriquecimento mútuo das pessoas. 0 ciberespaço seria o espaço móvel das interações entre conhecimentos e conhecedores de coletivos inteligentes sem territórios”. LÉVY, Pierre. A inteligência coletiva: por uma antropologia do ciberespaço. 5 ed. São Paulo: Loyola, 2007. p. 31.

${ }^{18}$ RADFAHRER, Luli. In: SPYER, Juliano (Org). Para entender a internet: noções, práticas e desafios da comunicação em rede. 2009. Disponível em: <www.esalq.usp.br/biblioteca/PDF/ Para_entender_a_ Internet.pdf>. Acesso em: 5 ago. 2012.p. 28.

${ }^{19}$ GUZZI, Drica. Web e participação: a democracia no século XXI. São Paulo: Senac São Paulo, 2010.p. 35.

REDESG / Revista Direitos Emergentes na Sociedade Global - www.ufsm.br/redesg v. 1, n. 1, jan.jun/2012
} 
ISSN 2316-3054

$\mathrm{Na}$ seara política, esta troca facilitada entre internautas e a desnecessidade de autorização para expressar-se fomentam discussões, ampliam a motivação para participar e aumentam a gama e a diversidade de cooperação. 0 simples fato de existir um espaço aberto a todos, ainda que virtual, torna-se incentivador, resultando em um interesse maior na política.

Consequentemente, surgem novas formas de manifestação popular de repúdio ou aceitação de atos, projetos e decisões tomadas por políticos. Ainda melhor, é possível acreditar que através de movimentos criados online, a sociedade civil alcance mudanças significativas em posicionamentos ou políticas ainda em discussão. Se por décadas o eleitor somente poderia exercer seus direitos, punir ou parabenizar políticos por meio do voto, atualmente outros instrumentos se apresentam, mais céleres e potentes.

Dentre os locais acessados, revela significativo crescimento a utilização dos blogs como nítido exemplo encontrado na web 2.0 para a construção da ciberdemocracia, diante das características que thes são peculiares e incentivadoras, conforme será analisado abaixo.

\section{A CONSTRUÇÃO DA PARTICIPAÇÃO DEMOCRÁTICA EM BLOGS}

Os blogs, a princípio, são tratados como espaços pessoais (embora existam blogs coletivos), nos quais o proprietário escreve livremente sobre temas de seu interesse pessoal, dirigidos a toda coletividade, pois não se impõe um prévio cadastro para acessá-lo (com exceção do microblog ${ }^{20}$ Twitter $^{21}$ ). Eles podem ter conteúdo educativo, técnico, informativo, de lazer, entre outros. José Luis Orihuela ${ }^{22}$ conceitua os blogs como:

\footnotetext{
${ }^{20}$ Microblog ou microblogging consiste numa forma de publicação de blog que permite fazer atualizações breves de texto, geralmente limitado a 200 caracteres. Os textos podem ser publicados e enviados por SMS, Messenger, Skype, e-mail, mp3 ou pela Internet. UTRINE, Marcelo. (Coord.) Twitter: Influenciando Pessoas \& Conquistando o Mercado! Rio de Janeiro: Alta Books, 2009. p. 43

${ }^{21}$ O Twitter foi desenvolvido pelos programadores Evan Williams, Jack Dorsey e Biz Stone e lançado oficialmente em outubro de 2006. O objetivo inicial era responder a pergunta "What's happing? (O que está acontecendo)", sendo considerado um microblog pela limitação de até 140 caracteres para responder aos questionamentos dos usuários ou para inserir links de textos, imagens, vídeos ou páginas na Internet. A explicação para a expressão Twitter para denominar essa rede social é devido ao fato deste termo significar, em inglês, a pronúncia de um conjunto de sons emitidos pelos pássaros que têm a função de atrair outros seres da mesma espécie, raça ou bando. UTRINE, Marcelo. (Coord.) Twitter: Influenciando Pessoas \& Conquistando o Mercado! Rio de Janeiro: Alta Books, 2009. p. 47

${ }_{22}$ ORIHUELA, José Luis. Blogs e blogosfera: o meio e a comunidade. In: ORDUÑA, Octavio. I. Rojas; ALONSO, Julio; ANTÚNEZ, José Luis; ORIHUELA, José Luis; VARELA, Juan. Blogs: revolucionando os meios de comunicação. São Paulo: Thomson Learning, 2007. p. 2.

REDESG / Revista Direitos Emergentes na Sociedade Global - www.ufsm.br/redesg v. 1, n. 1, jan.jun/2012
} 
ISSN 2316-3054

Weblogs ou blogs são páginas pessoais da web que, à semelhança de diários online, tornam possível a todos publicar em rede. Por ser a publicação on-line centralizada no usuário e nos conteúdos, e não na programação ou no design gráfico, os blogs multiplicaram o leque de opções dos internautas de levar para a rede conteúdos próprios sem intermediários, atualizados e de grande visibilidade para os pesquisadores.

Encontra-se nos blogs uma forma diferenciada de publicação na web, pois é o próprio detentor quem faz as postagens (ou "posts"), escolha do conteúdo, cor e forma, sem necessitar de um programador ou técnico para manutenção e atualização e são, em sua maioria, gratuitos. Ao assumir a responsabilidade pela difusão de conteúdo, os blogs (e também as páginas pessoais, fóruns, chats, listas de discussão) dão origem ao fenômeno da auto edição, em que o indivíduo sai de uma posição passiva para assumir o papel de emissor de informações e tornar as suas mensagens acessíveis a um sem número de pessoas ${ }^{23}$.

Ao postar em seu blog o conteúdo que julgar interessante, o blogueiro ${ }^{24}$ o faz no topo da página, onde se pode encontrar o dia e horário da postagem, bem como o nome ou apelido daquele que o fez. Referido formato permite aos visitantes a realização de um acompanhamento do blog, lendo as publicações de forma cronologicamente inversa, ou seja, sempre da publicação mais recente para a mais antiga ${ }^{25}$.

Ainda, com relação às postagens, encontra-se um diferencial dos blogs: a sua frequência. O proprietário tem ampla liberdade para escrever conforme apresente tempo, vontade, inspiração ou algum fato que almeje relatar e publicar. Embora o blog seja reconhecido como um transmissor e um espaço de discussão, não há nenhum vínculo ou obrigatoriedade na publicação, diferentemente do que ocorre nos meios de comunicação tradicionais, a exemplo do jornal, em que todos os dias deve apresentar, obrigatoriamente, conteúdo para impressão.

A instantaneidade com que as informações são veiculadas é outra característica marcante, pois estas podem ser publicadas a qualquer momento, independentemente do

23 AMARAL, Inês. A emergência dos weblogs enquanto novos actores sociais. Disponível em: <http://prisma.cetac.up.pt/artigospdf/3_ines_amaral_prisma.pdf>. Acesso em: 25 jul. 2012. p. 46-47.

${ }^{24}$ Blogueiro é o termo designado para se referir ao dono do blog, ou a pessoa que edita o conteúdo disponibilizado na página, bem como as pessoas que postam frequentemente em páginas pessoais da web. RODRIGUES, Catarina. Blogs: uma ágora na net. Disponível em: <http://labcom.ubi.pt/files/agoranet04/rodrigues-catarina-blogs-agora-na-net.pdf>. Acesso em: 30 jul. 2012. p. 04.

${ }^{25}$ LUCCIO, Flavia Di; COSTA, Nicolaci da. Escritores de blogs: interagindo com os leitores ou apenas ouvindo ecos? Disponível em: <http://pepsic.bvs-psi.org.br/pdf/pcp/v27n4/v27n4a08.pdf>. Acesso em: 10 ago. 2012. p. 668.

REDESG / Revista Direitos Emergentes na Sociedade Global - www.ufsm.br/redesg v. 1, n. 1, jan.jun/2012 
ISSN 2316-3054

horário, edição ou tiragem. Reflete uma característica típica da própria Internet, qual seja, a velocidade na transmissão de dados, pois estes podem estar sendo publicados ao mesmo tempo em que o fato ou evento está ocorrendo.

O crescimento da utilização dos blogs confunde-se com o próprio desenvolvimento da Internet, meio que lhe dá sustentação, pois as comunidades virtuais "transcendem a distância, a baixo custo, costumam ter natureza assincrônica, combinam a rápida disseminação da comunicação de massa com a penetração da comunicação pessoal, e permitem afiliações múltiplas em comunidades parciais" ${ }^{26}$.

Não se pode olvidar de outro elemento que compõe os blogs e denota relevante instrumento de participação: o link chamado "comentários" ou, ainda, “livro de visitas”, que é o espaço para comentários dos visitantes daquele blog. É o local em que os internautas que visitam o blog podem nele comentar, fazer críticas ou sugestões a respeito dos textos lidos e, também, indicar o seu próprio blog ou os de amigos, formando-se assim, uma rede de interação, em que uns referem-se a outros blogs, formando uma verdadeira "comunidade", pois os comentários ficam acessíveis a todos que visualizarem aquela página ${ }^{27}$.

Geralmente esta "rede de interação" desenvolve-se a partir do post original. Entretanto, como alertam Alex Primo e Ana Smaniotto ${ }^{28}$, "nada impede que a conversa tome outros rumos ou mesmo que se publique comentários fora do contexto. Vários assuntos podem ser discutidos ao mesmo tempo, mesmo aqueles sem nenhuma relação ao post original”.

Notável é a alteração da posição do cidadão que, de mero expectador, passou, com o advento da Internet, a emissor e difusor de conteúdo, favorecendo a prática ativista e democrática, como salienta Ronald Sanson Stresser Junior ${ }^{29}$ :

Esta universalização promovida pela internet, sem paralelos na história da humanidade, acaba de certa forma favorecendo a prática ativista. 0 ciberativista pode facilmente captar as imagens de que precisa para defender seu ideal, editar um texto que dê apoio a estas imagens, e rapidamente disponibilizar este

\footnotetext{
${ }^{26}$ CASTELLS, Manuel. A sociedade em rede. A era da informação: economia, sociedade e cultura; v.1. São Paulo: Paz e Terra, 1999 . p.446.

27 AMARAL, Adriana; RECUERO, Raquel; MONTARDO, Sandra. Blogs.com: estudos sobre blogs e comunicação. São Paulo: Momento Editorial, 2009. p.79.

28 PRIMO, Alex; SMANIOTTO, Ana Maria Reczek. Blogs como espaços de conversação: interações conversacionais na comunidade de blogs insanus. Disponível em: <http://www6.ufrgs.br/limc/PDFs/conversacao.pdf>. Acesso em: 12 ago. 2012. p.05.

29 STRESSER JUNIOR, Ronald Sanson. Ciberativismo - a política 2.0. Disponível em: <http://pt.scribd.com/doc/32350802/CIBERATIVISMO-A-POLITICA-2-0-Ronald-S-Stresser-Jr>. Acesso em: 1 ago. 2012. p.5.
}

REDESG / Revista Direitos Emergentes na Sociedade Global - www.ufsm.br/redesg v. 1, n. 1, jan.jun/2012 
ISSN 2316-3054

conteúdo em rede, atingindo seu público-alvo com eficácia e presteza. Hoje todos somos produtores de conteúdo.

Embora a maioria das pessoas considere o blog apenas como um "diário pessoal", em que o proprietário faz um registro periódico de sua vida, utilizando-se de imagens, letras de músicas, entre outros, não se pode desconsiderar que, atualmente, em razão do expressivo número de acessos, postagens e comentários, os blogs estão assumindo outra faceta.

Chega-se à referida conclusão pelo fato que, na Pesquisa TIC Domicílios 2010, realizada pelo Comitê Gestor da Internet no Brasil, constatou-se que dentre as atividades mais procuradas pelos internautas destacam-se: enviar e receber e-mails $(80 \%)$, enviar mensagens instantâneas (74\%), participar de sites de relacionamento (70\%) e participação dos usuários de Internet em microblogs, como o Twitter, por exemplo, $(14 \%)^{30}$.

A pesquisa constatou que os internautas estão dispostos a participar ativamente de ações na Internet, tais como o envio e recebimento de mensagens instantâneas e a participação em redes de relacionamento, demonstrando a tendência para um ativismo digital em direção à construção de uma ciberdemocracia.

A título ilustrativo, Alex Primo ${ }^{31}$ divide os blogs em dezesseis gêneros, observando-se as condições como número de redatores, impacto de condicionamentos profissionais e estilos de texto. Dentre estes, insta destacar o gênero profissional, o qual é escrito por um especialista na área, que "reconhece a credibilidade de seus textos, reflete a reputação construída no tempo, em virtude do sucesso de suas ações como profissional”. Também merece destaque o gênero grupal, o qual é produzido por pelo menos duas pessoas, cujo foco são temas de interesse do grupo, bem como o convívio dos participantes e a troca de informações.

Pode-se incluir o Twitter como uma espécie de blog (ou microblog, já que as mensagens podem ter no máximo 140 caracteres) do gênero grupal, porque cada indivíduo "segue" as atualizações de páginas de pessoas que the interessam e, assim, forma sua própria rede de contatos, recebendo, de forma instantânea, as atualizações promovidas por aquela pessoa que está "seguindo".

${ }^{30}$ CGI.BR. Comitê Gestor da Internet no Brasil. TIC Domicílios e Empresas 2010. Disponível em: <http://op.ceptro.br/cgi-bin/indicadores-cgibr-2010?pais=brasil\&estado=rs\&academia=academia\&age=de16-a-24-anos\&education=superior\&purpose=pesquisa-academica>. Acesso em: 09 ago. 2012. p.160.

31 PRIMO, Alex. Blogs e seus gêneros: avaliação dos 50 blogs mais populares em língua portuguesa. Disponível em: <http://www6.ufrgs.br/limc/PDFs/50_blogs.pdf>. Acesso em: 12 ago. 2012. p.2.

REDESG / Revista Direitos Emergentes na Sociedade Global - www.ufsm.br/redesg v. 1, n. 1, jan.jun/2012 
ISSN 2316-3054

O Twitter tem se transformado em uma tecnologia revolucionária e em uma arma posta à disposição dos internautas e da sociedade civil mundial, pois possibilitou que revoluções no mundo árabe, mesmo após o corte dos sistemas de comunicação como Internet e celular, fossem possíveis através do envio de mensagens de voz após a criação da central de mensagens curtas do Twitter em parceria com a empresa Google ${ }^{32}$.

Para tanto, é necessário o prévio cadastro no site, com a criação de um perfil e posterior publicação de mensagens (ou "feeds") e acompanhamento daqueles perfis que the interessam, seja por razões de amizade, laços familiares, interesses comuns ou mesmo debates de temática da atualidade ${ }^{33}$.

A “blogosfera", ou seja, o conjunto de blogs, materializou uma verdadeira revolução na área da comunicação, aumentando-se significativamente o número de emissores e de produtores de informação, área que, antes do advento da Internet, restringia- se aos jornalistas. 0 uso dos blogs tem servido para veiculação de notícias, anúncios para obtenção de dinheiro gasto em campanhas eleitorais e também para realização de enquetes e oitiva da população que os acessa e tem interesse naquela temática discutida, bem como o envio instantâneo de links de notícias e a mobilização para a participação de eventos.

Resta evidente que o uso da Internet não está mais vinculado à simples consulta por informações ou uso de e-mails, mas a uma nova forma de interação e expressão da população, que passa a pesquisar e a discutir temas de relevante interesse nacional, a exemplo da petição online que postulou a criação da Lei da Ficha Limpa ${ }^{34}$.

Especificamente no tocante aos blogs, estes deixaram de ser apenas um "diário pessoal" de seu proprietário para influenciar e incitar a população a se manifestar sobre os mais variados

\footnotetext{
32 MALBERGIER, Sérgio. A revolução (árabe) será twittada. Publicado em 02 fev. 2011. Disponível em: <http://www1.folha.uol.com.br/colunas/sergiomalbergier/869376-a-revolucao-arabe-seratwittada.shtml> Acesso em: 10 ago. 2012.

33 JUNGHERR, Andreas. La guia diactive para uso de Twitter com fines de activismo. Disponível em: <http://pt.scribd.com/doc/53853226/Twitter-Guia>. Acesso em: 06 ago. 2012. p.5.

${ }^{34}$ A "Campanha Ficha Limpa" foi lançada em abril de 2008 com o objetivo de melhorar o perfil dos candidatos a cargos eletivos do país, através da elaboração de um Projeto de Lei de iniciativa popular que leva em conta vida pregressa, tornando mais rígidos os critérios de inelegibilidades (Lei Complementar $\mathrm{n}^{\circ}$ 135/2010). Houve significativa participação da população no debate do assunto, uma vez que o perfil da campanha no Twitter '@fichalimpa' teve mais de treze mil e novecentos seguidores. CAMPANHA Ficha Limpa. Disponível em: <http://twitter.com/\#!/fichalimpa> Acesso em: 28 jul. 2012. No Facebook o número de pessoas que curtiram o perfil 'MCCE Ficha Limpa' ultrapassou quarenta e um mil e novecentos acessos. MCCE Ficha Limpa. Disponível em: <http://pt-br.facebook.com/MCCEFichaLimpa>. Acesso em: 28 jul. 2012. Nos dois perfis ainda é possível fazer manifestações e comentários sobre questões que envolvem política e corrupção.
}

REDESG / Revista Direitos Emergentes na Sociedade Global - www.ufsm.br/redesg v. 1, n. 1, jan.jun/2012 
ISSN 2316-3054

temas, dentre eles a discussão de leis e temas políticos, influenciando diretamente na esfera pública de nossa sociedade.

Novamente invoca-se a posição de emissor do cidadão, a fim de ponderar a existência de uma horizontalidade nas relações, uma vez que através dos blogs não há um prévio controle acerca da temática a ser publicada e nem um direcionamento de opinião, deixando ao cibernauta a opção de livremente navegar entre os mais variados espaços para, então, debater e chegar às suas próprias conclusões.

O espaço oferecido pelos blogs constitui em uma importante ferramenta do debate público, já que o conteúdo ali postado será acessado por uma infinidade de pessoas, muitas vezes, sem conhecimento acerca da personalidade do proprietário do blog, mas que com ele compartilham ideais, pensamentos ou mesmo críticas.

A utilização dos blogs para construção de uma ciberdemocracia advém da característica de atuação como uma verdadeira ágora digital ${ }^{35}$, na medida em que o debate mediado pela Internet não apresenta limites territoriais ou temporais, podendo participar todos aqueles que detenham acesso à rede e interesse no debate.

A existência de mais de 152 milhões de blogs ao redor do mundo, consoante pesquisa realizada no ano de $2010^{36}$, ao mesmo tempo em que ratifica a importância da existência de espaços para construção de debate livre na Internet, leva ao seguinte questionamento: estes espaços são utilizados para os fins em que foram criados, qual seja, a promoção do debate público de forma democrática?

Após uma breve apresentação acerca das possibilidades de ciberdemocracia na Internet, com especial atenção àquelas proporcionadas pelo uso dos blogs, resta analisar como isto ocorre na prática, uma vez que quando o tema relaciona-se com meios alternativos e modernos de

\footnotetext{
35 Segundo Catarina Rodrigues: "Recorde-se que a ágora era a praça pública onde se realizavam as assembleias (do povo e do exército, por exemplo) e reuniões de carácter comercial, cívico, político e religioso na Grécia Antiga, um espaço onde todos podiam expor as suas ideias, sugestõese propostas. Para muitos, essa ágora foi o verdadeiro berçoda democracia, uma vez que aí os cidadãos praticavam a liberdadede pensamento e expressão em domínios como asartes, a política e a filosofia. Acontece que os blogs constituemum espaço onde qualquer pessoa (que tenha acesso àlnternet) pode dizer o que pensa sobre um determinado assunto, um espaço que proporciona a troca de conhecimentoe muitas vezes impulsiona o debate. Transpomos assim aágora, que ocupava na sua génese um espaço físico, umapraça pública delimitada, para um espaço virtual proporcionado pela Internet”. RODRIGUES, Catarina. Blogs: uma ágora na net. Disponível em: <http://labcom.ubi.pt/files/agoranet04/rodrigues-catarina-blogs-agorana-net.pdf>. Acesso em: 30 jul. 2012. p. 29.

36 AVELAR; DUARTE. Consultoria e design. Estatísticas sobre blogs. Disponível em: <http://www.avellareduarte.com.br/projeto/conceitos/ferramentasgestao/ferramentasgestaoha.htm>. Acesso em: 26 jul. 2012.

REDESG / Revista Direitos Emergentes na Sociedade Global - www.ufsm.br/redesg v. 1, n. 1, jan.jun/2012
} 
ISSN 2316-3054

comunicação, poucos são os estudos que apresentam dados concretos sobre a utilização da web por internautas frente à teoria. Por estas razões, no próximo tópico será avaliada a lista dos blogs mais acessados no ano de 2011 no Brasil, a fim de se concluir de que forma o brasileiro tem utilizado esta ferramenta.

\section{A UTILIZAÇÃO DOS BLOGS NO BRASIL: RANKING DOS 20 BLOGS MAIS ACESSADOS NO ANO DE 2011}

Inicialmente, cabe ressaltar que inexistem pesquisas oficiais que apresentem os rankings pretendidos, uma vez que, apesar do tema ser atual, grande parte das pessoas não the atribui importância, justamente por desconhecer as características da blogosfera brasileira. Ainda imagina-se que blogs sejam páginas de cunho pessoal, sem grande relevância para a sociedade como um todo. Entretanto, isso se mostra um equívoco, porquanto a maioria dos blogs listados não apresenta esta qualidade.

O ranking utilizado para esta análise provém do blog Web Dig: Tecnologia e Redes Sociais. Criado em 2010 por um designer, Jefferson Meneses, o blog possui a “[...] missão de espalhar conhecimento e agregar novas culturas em um espaço onde o conhecimento pode ser livre" ${ }^{37}$. De acordo com o proprietário, o blog é independente, mantido e organizado pelo mesmo, e “[...] se dedica a cobertura das mídias digitais e ao acompanhamento e desenvolvimento de novas tecnologias e em especial das Redes Sociais"38.

No pertinente à lista de blogs mais acessados no Brasil, o resultado obtido foi uma combinação de dados fornecidos por outros dois sites: o AdPlannerda Google e o Alexa Top Sites Brasil. De acordo com o Autor do post:

A lista "Alexa Top Sites" é ordenada com base no ranking de tráfego mensal, que é calculado usando uma combinação de média de visitantes diários e visualizações de páginas ao longo do mês anterior.

Com o Ad Planner, vamos conferir e conferir os PageViews destes sites e blogs, segundo a Google.

37 MENESES, Jefferson. Editorial e Contatos. Disponível em: <http://www.webdig.com. $\mathrm{br} /$ sobre/\#ixzz23Wmbcp5P >. Acesso em 31 jul.2012.

${ }^{38}$ Ibidem.

REDESG / Revista Direitos Emergentes na Sociedade Global - www.ufsm.br/redesg v. 1, n. 1, jan.jun/2012 
Apenas lembro que não devemos confundir "popularidade com audiência", nenhum desses rankings é baseado em audiência, existe apenas uma estimativa ${ }^{39}$ (grifos no original).

A lista final dos blogs mais acessados no ano de 2011 no Brasil, de acordo com o Web Dig: Tecnologias e Redes Sociais, é a seguinte ${ }^{40}$ :

1. Kibe Loco - Posição 153

2. Mundodastribos - Posição 175

3. Minilua.com - Posição 191

4. Não Salvo - Posição 208

5. Sempre Tops - Posição 243

6. Central Blogs - Posição 248

7. ahnegao.com.br - Posição 256

8. Não Intendo - Posição 268

9. Mestre SEO - Posição 271

10. Testosterona - Posição 308

11. Ferramentas Blog - Posição 338

12. Mac Magazine - Posição 353

13. Jacaré Banguela - Posição 360

14. Gizmodo Brasil - Posição 368

15. Sedentário e Hiperativo - Posição 378

16. Blog do Cupom - Posição 384

17. Bobagento - Posição 483

18. TecnoBlog - Posição 489

19. Insoonia - Posição 503

20. Blog do Iphone - Posição 512

Sendo a primeira classificação relativa aos 20 blogs mais acessados, a posição que está ao lado refere-se ao lugar em que a respectiva página restou dentre todos os sites (em sentido

39 Idem. Lista dos Sites e Blogs mais acessados em 2011. 15 nov.11. Disponível em: <http://www.webdig.com.br/9015/lista-dos-sites-e-blogs-mais-acessados-em-2011/\#ixzz23Wpn1BhP>. Acesso em 31 jul.2012.

40 MENESES, Jefferson. Editorial e Contatos. Disponível em: <http://www.webdig.com. br/sobre/\#ixzz23Wmbcp5P >. Acesso em 31 jul.2012.

REDESG / Revista Direitos Emergentes na Sociedade Global - www.ufsm.br/redesg v. 1, n. 1, jan.jun/2012 
ISSN 2316-3054

amplo) mais acessados. Nesse sentido, se considerado que essa lista inclui os maiores sites da internet, acessados pela massa (como exemplo, Google, Facebook, Youtube, Uol e outros), temse que o primeiro blog mais acessado no Brasil não se encontra tão distante no ranking. Isso porque o blog mantém suas características básicas, como, por exemplo, pertencer a uma pessoa física "anônima”, ou seja, sem patrocínios milionários ou publicidade intensa. A “fama” destes blogs origina-se da própria rede, principalmente por meio da indicação entre internautas, como ocorreu com os primeiros blogs que surgiram.

Ainda em um exame geral das listagens, entre os sites mais acessados no país, o conhecido Blogger está na sétima posição, à frente de renomados como Orkut, Yahoo e Terra ${ }^{41}$. O Twitter, considerado como microblog, encontra-se em décimo primeiro lugar, sendo preferido a outros como MSN, iG, Wikipedia, Mercado Livre, entre outros ${ }^{42}$. Por fim, o Wordpress, outra plataforma que hospeda blogs, encontra-se em décimo sétimo, antes dos conhecidos Babylon e 4Shared ${ }^{43}$.

Constatada a inserção e relevância dos blogs no ambiente da rede mundial de computadores, resta analisar quais são as temáticas que envolvem os Top 20 Blogs no Brasil.

o blog número 1 de acessos é o KibeLoko (http://kibeloco.com.br). Trata-se de uma opção de lazer, que traz conteúdos humorísticos em média quatro vezes por dia a seus leitores. Apesar de ser considerado ainda um blog, tendo em vista seu formato, dinamicidade e periodicidade, todo o conteúdo postado está hospedado em um site, como se visualiza no endereço acima indicado. A justificativa para isso está muito provavelmente ligada ao crescimento de acessos e visibilidade do blog, porquanto a "transformação" ocorreu ainda no mês de abril de 2007. O primeiro endereço (http://kibeloco.blogspot.com.br), vinculado ao blogspot, permanece existindo, entretanto apenas abriga os conteúdos antigos, do ano de 2003 até o último post em $2007^{44}$.

0 segundo e terceiro blogs elencados no ranking são bastante semelhantes no pertinente a conteúdos postados e forma diferenciada de disposição de informações. O Mundo das Tribos (http://www.mundodastribos.com/), de forma geral, traz notícias sobre os mais variados assuntos, entre notícias, esportes, entretenimento, tecnologia, etc. Está hospedado no R7, site da Rede Record de TV, e "tem por intuito reunir todas as tribos com diferentes

\footnotetext{
41 Ibidem.

42 Ibidem.

43 Ibidem.

${ }^{44}$ KIBELOKO. Disponível em: <http://kibeloco.blogspot.com.br/>. Acesso em: 30 jul. 2012.
}

REDESG / Revista Direitos Emergentes na Sociedade Global - www.ufsm.br/redesg v. 1, n. 1, jan.jun/2012 
ISSN 2316-3054

informações"45. Já o Minilua (http://minilua.com/), é um blog no qual se apresentam curiosidades em geral, com grande frequência de postagens. Apesar do endereço não remeter a nenhuma plataforma de blogs, em seu F.A.Q. com as perguntas mais frequentes, os Autores explicam que "o Minilua é um blog comum (WordPress) com postagens diárias"46.

O NãoSalvo (http://www.naosalvo.com.br/), que aparece em quarto lugar, assim como o KibeLoko e inúmeros outros listados (Ah Negão, Não Intendo, Testosterona, Jacaré Banguela, Sedentário e Hiperativo, Bobagento e Insoonia), é um blog de humor com inúmeras curiosidades e temas de entretenimento. É perceptível que esse tipo de página atrai muitos internautas, provavelmente pelo fato de ser divertido e de fácil compreensão, sem exigir esforço do leitor ${ }^{47}$.

Em sexto lugar encontra-se o Central Blogs (http://www.centralblogs.com.br), que é um diretório de blogs, ou seja, um banco de dados com milhares de blogs cadastrados e que podem ser encontrados com uma simples busca nesta página. Em décimo primeiro lugar, está o Ferramentas Blog (http://www.ferramentasblog.com), idealizado por Marcos Lemos, graduado em Teologia pela PUC-Minas Belo Horizonte e graduando em Letras pela INESP/UEMG Divinópolis, no intuito de "partilhar sua experiência com outros blogueiros/bloggers" 48

Ainda dentro do ranking analisado, outro grupo temático chama a atenção: o tecnológico. Na lista, representadas pelos blogs Mac Magazine, Gizmodo Brasil, Tecnobloge Blog do Iphone, referidas páginas versam sobre tecnologia, aparelhos eletrônicos e atualidades no mundo dos computadores e afins.

Por fim, um último seguimento de blog ainda não analisado é o do Blog do Cupom (http://www.blogdocupom.com.br), que nasceu em maio de 2011 e reúne todas as dicas e oportunidades de compras coletivas no Brasil. Além de indicar os grupos mais confiáveis, dar dicas para o consumidor e trazer notícias e novidades no ramo, o blog abre um espaço para reclamações acerca de negócios realizados com os principais grupos de compras coletivas, sendo uma útil ferramenta ao consumidor. Está em décimo sexto lugar na lista.

Interessantes são, também, as tabelas organizadas, em categorias, de acordo com as pesquisas realizadas - como a lista “Alex top sites" -, a exemplo do site Top 10+

\footnotetext{
45 SOBRE O MUNDODASTRIBOS. Disponível em: <http://www.mundodastribos.com/ sobre>. Acesso em: 03 ago. 2012.

${ }^{46}$ NOS BASTIDORES do Minilua F.A.Q.: \#3. Disponível em: <http://minilua.com/nos-bastidores-minilua-3/>. Acesso em: 03 ago. 2012.

${ }^{47}$ NÃOSALVO. Disponível em: <http://www.naosalvo.com.br/>. Acesso em: 13 ago. 2012.

${ }^{48}$ SOBRE. Ferramentas Blog. Disponível em: <http://www.ferramentasblog.com/sobre>. Acesso em: 30 jul. 2012.

REDESG / Revista Direitos Emergentes na Sociedade Global - www.ufsm.br/redesg v. 1, n. 1, jan.jun/2012
} 
ISSN 2316-3054

(http://top10mais.org/top-10-melhores-blogs-de-moda-do-brasil/) que traz o ranking dos dez blogs mais acessados que tratam sobre moda. Neste site, utilizou-se não somente a lista acima mencionada, como também a pontuação de 0 a 10 , conferida pelo Google, chamada de PageRank, que pontua os blogs de acordo com o número de recomendações. Ou seja, quanto mais recomendado for o blog, maior será a sua pontuação e, consequentemente, a sua popularidade. Ainda, para a elaboração da lista, utilizou-se o número de seguidores no Twitter e Facebook $^{49}$.

Após esta análise, acerca dos principais tipos de blogs acessados pelos brasileiros, temse que prevalecem os temas acerca de entretenimento, notícias e novidades em geral. Os blogs ainda são utilizados como ferramentas de comunicação entre internautas anônimos, que se arranjam de acordo com afinidades e interesses pessoais. No entanto, uma característica antes tida como sinônimo de blog já não se confirma: em nenhum dos endereços analisados encontrouse os blogs estilo diário pessoal.

Apesar de existir, a possibilidade de construção de uma ciberdemocracia mediante o uso de blogs, aparentemente está distante de ocorrer no Brasil. 0 grande público internauta ainda prefere utilizar essas páginas de acordo com interesses pessoais, sem um intuito primordial de aproveitar este novo ambiente para a criação de um novo espaço de discussão e construção civil.

No entanto, deve-se ater ao fato de que a blogosfera brasileira é imensurável; são milhões de blogs, que indubitavelmente não podem ser generalizados em uma amostra tão singela de vinte exemplos. Se o acesso à Internet cresce de forma avassaladora, seguramente também a participação dos internautas crescerá, seja com a criação de novos blogs ou com a participação nos já existentes. Caberá ao próprio cidadão brasileiro modificar esse contexto desanimador, vislumbrando não somente uma melhora na qualidade do mundo virtual, mas o desenvolvimento da sociedade na qual se insere.

\section{CONCLUSÃO}

Cotidianamente, impossível se mostra qualquer tentativa no sentido de negar a utilidade e relevância que a Internet apresenta, uma vez que relações são criadas,

49 TOP10. Top 10 melhores blogs de moda do Brasil. Disponível em: <http://top10mais.org/top-10melhores-blogs-de-moda-do-brasil/>. Acesso em: 13 ago. 2012.

REDESG / Revista Direitos Emergentes na Sociedade Global - www.ufsm.br/redesg v. 1, n. 1, jan.jun/2012 
ISSN 2316-3054

conhecimentos são aumentados e novos espaços de participação, criados, já que se mostra como um meio de fácil e rápido acesso, além do baixo custo.

Entretanto, apesar de no meio acadêmico e nas classes mais abastadas da sociedade o acesso ser frequente e de importância destacada, uma vez que a rede mundial de computadores deixou de ser apenas um local de confraternização e lazer para passar à função de ambiente de trabalho e de troca de conhecimento, a utilização conferida pela população em nosso país ainda é um fator que não pode ser desconsiderado, quando quer se tratar do exercício da ciberdemocracia na blogosfera.

Referida assertiva merece destaque na medida em que o país ainda vive uma contradição em termos de acesso à Internet, pois embora sejam constatados avanços anuais no número de usuários, a população conectada à blogosfera não demonstra interesse, de uma forma geral, na participação em assuntos governamentais, uma vez a grande preferência nacional é o acesso a blogs de relacionamento, lazer, notícias e moda, ou seja, para entretenimento.

É o que se comprova ao examinar a lista dos blogs mais acessados no Brasil. Dos vinte citados, ao menos dez são páginas voltadas para humor e curiosidades, sem compromisso com questões políticas ou de importância social no contexto brasileiro; outros seis são direcionados a assuntos tecnológicos, acerca de máquinas e modernidades eletrônicas; os que restam são uma mistura de informações e dicas ao internauta, sobre os mais variados assuntos, sendo claro que em nenhum dos vinte existe algum blog com fins políticos ou de caráter educativo.

Essa conclusão, sem dúvidas, confere aos ciberpessimistas alguma razão ao afirmar que a Internet muito mais aliena do que constrói mentes pensantes. Entretanto, não se pode olvidar a blogosfera brasileira é gigantesca. Tomar apenas a amostra de um pequeno número de blogs com grande popularidade não exclui totalmente a possibilidade de um avanço no que se refere a uma democracia online no Brasil, ou, ao menos, no exercício de uma possível democracia, fundada em uma construção legítima de ideias entre cidadãos.

Não se pode entender a realidade brasileira de 2011, no que tange aos blogs, como um sinal de fracasso da ciberdemocracia no país, pelo contrário. O Brasil ainda engatinha no quesito da inserção tecnológica, mas, assim como o aumento de acesso à Internet, também o acesso à informação e o interesse por assuntos que envolvem a nação irão crescer, se forem instigados. 0 fato dos blogs serem conhecidos e apreciados pela população é um grande passo para que eles continuem sendo uma ferramenta que, no futuro, tratará de assuntos de maior relevância nacional, como questões políticas, sociais, educacionais e afins. 
ISSN 2316-3054

Portanto, tendo em vista que o potencial de utilização dos blogs pelos internautas brasileiros para o alcance de uma ciberdemocracia ainda está distante - uma vez que a população desconhece o poder permitido por essas páginas abertas -, a esperança de que eles se tornem uma importante ferramenta para alcançar este objetivo democrático, para o futuro, permanece viva.

\section{REFERÊNCIAS}

AMARAL, Adriana; RECUERO, Raquel; MONTARDO, Sandra. Blogs.com: estudos sobre blogs e comunicação. São Paulo: Momento Editorial, 2009.

AMARAL, Inês. A emergência dos weblogs enquanto novos actores sociais. Disponível em: <http://prisma.cetac.up.pt/artigospdf/3_ines_amaral_prisma.pdf>. Acesso em: 25 jul. 2012.

AVELAR; DUARTE. Consultoria e design. Estatísticas sobre blogs. Disponível em:

<http://www.avellareduarte.com.br/projeto/conceitos/ferramentasgestao/ferramentasgestaoh a.htm>. Acesso em: 26 jul. 2012.

CAMPANHA Ficha Limpa. Disponível em: <http://twitter.com/\#!/fichalimpa> Acesso em: 28 jul. 2012.

CARDOSO, Gustavo. A mídia na sociedade em rede: filtros, vitrines, notícias. Rio de Janeiro: FGV, 2007.

CASTELLS, Manuel. A sociedade em rede. A era da informação: economia, sociedade e cultura; v.1. São Paulo: Paz e Terra, 1999.

CGI.BR. Comitê Gestor da Internet no Brasil. TIC Domicílios e Empresas 2010. Disponível em: <http://op.ceptro.br/cgi-bin/indicadores-cgibr-

2010? pais=brasil\&estado=rs\&academia=academia\&age $=$ de $-16-a-24-$

anos\&education=superior\&purpose=pesquisa-academica>. Acesso em: 09 ago. 2012.

GUZZI, Drica. Web e participação: a democracia no século XXI. São Paulo: Senac São Paulo, 2010.

JUNGHERR, Andreas. La guia diactive para uso de Twitter com fines de activismo. Disponível em: <http://pt.scribd.com/doc/53853226/Twitter-Guia>. Acesso em: 06 ago. 2012.

LEMOS, André; LÉVY, Pierre. O futuro da internet: em direção a uma ciberdemocracia. 2. ed. São Paulo: Paulus, 2010.

LÉVY, Pierre. A inteligência coletiva: por uma antropologia do ciberespaço. 5 ed. São Paulo: Loyola, 2007. 
LÉVY, Pierre. Ciberdemocracia. Lisboa: Instituto Piaget, 2003.

LUCCIO, Flavia Di; COSTA, Nicolacida. Escritores de blogs: interagindo com os leitores ou apenas ouvindo ecos? Disponível em: <http://pepsic.bvs-

psi.org.br/pdf/pcp/v27n4/v27n4a08.pdf>. Acesso em: 10 ago. 2012.

KIBELOKO. Disponível em: <http://kibeloco.blogspot.com.br/> Acesso em: 30 jul.2012.

Malbergier, Sérgio. A revolução (árabe) será twittada. Publicado em 02 fev. 2011. Disponível em: <http://www1.folha.uol.com.br/colunas/sergiomalbergier/869376-a-revolucao-arabe-seratwittada.shtml> Acesso em: 10 ago. 2012.

MCCE Ficha Limpa. Disponível em: <http://pt-br.facebook.com/MCCEFichaLimpa> Acesso em: 28 jul. 2012.

MENESES, Jefferson. Editorial e Contatos. Disponível em: <http: / /www.webdig.com. br/sobre/\#ixzz23Wmbcp5P>. Acesso em 31 jul. 2012.

MENESES, Jefferson. Lista dos Sites e Blogs mais acessados em 2011. 15 nov.11. Disponível em: <http://www.webdig.com.br/9015/lista-dos-sites-e-blogs-mais-acessados-em-

2011/\#ixzz23Wpn1BhP>. Acesso em 31 jul. 2012.

NÃOSALVO. Disponível em: <http://www.naosalvo.com.br/>. Acesso em: 13 ago. 2012.

NOS BASTIDORES do Minilua F.A.Q.: \#3. Disponível em: <http://minilua.com/nos-bastidoresminilua-3/> Acesso em: 03 ago. 2012.

O’REILLY, Tim. 0 que é Web 2.0 - Padrões de design e modelos de negócios para a nova geração de software. Disponível em: <http://www.cipedya.com/doc/102010> Acesso em: 10 ago. 2012.

ORIHUELA, José Luis. Blogs e blogosfera: o meio e a comunidade. In: ORDUÑA, Octavio. I. Rojas; ALONSO, Julio; ANTÚNEZ, José Luis; ORIHUELA, José Luis; VARELA, Juan. Blogs: revolucionando os meios de comunicação. São Paulo: Thomson Learning, 2007.

PRIMO, Alex. Blogs e seus gêneros: avaliação dos 50 blogs mais populares em língua portuguesa. Disponível em: <http://www6.ufrgs.br/limc/PDFs/50_blogs.pdf>. Acesso em: 12 ago. 2012.

PRIMO, Alex; SMANIOTTO, Ana Maria Reczek. Blogs como espaços de conversação: interações conversacionais na comunidade de blogs insanus. Disponível em:

<http://www6.ufrgs.br/limc/PDFs/conversacao.pdf>. Acesso em: 12 ago. 2012.

RADFAHRER, Luli. In: SPYER, Juliano (Org). Para entender a internet: noções, práticas e desafios da comunicação em rede. 2009. Disponível em:

<www.esalq.usp.br/biblioteca/PDF/Para_entender_a_Internet.pdf>. Acesso em: 05 ago. 2012.

RECUERO, Raquel. Redes Sociais na Internet. Porto Alegre: Sulina, 2009.

REDESG / Revista Direitos Emergentes na Sociedade Global - www.ufsm.br/redesg v. 1, n. 1, jan.jun/2012 
ISSN 2316-3054

ESPAÇOS DE CONVERSAÇÃO: OS BLOGS E A CONSTRUÇÃO DA

CIBERDEMOCRACIA NO BRASIL

LETÍCIA BODANESE RODEGHERI

FRANCIELI PUNTEL RAMINELLI

RAFAEL SANTOS DE OLIVEIRA

RODRIGUES, Catarina. Blogs: uma ágora na net. Disponível em:

<http://labcom.ubi.pt/files/agoranet04/rodrigues-catarina-blogs-agora-na-net.pdf>. Acesso em: 30 jul. 2012.

SOBRE O MUNDODASTRIBOS. Disponível em: <http: //www. mundodastribos.com/ sobre>. Acesso em: 03 ago. 2012.

SOBRE. Ferramentas Blog. Disponível em: <http://www.ferramentasblog.com/sobre>. Acesso em 30 jul.2012.

STRESSER JUNIOR, Ronald Sanson. Ciberativismo - a política 2.0. Disponível em: <http://pt.scribd.com/doc/32350802/CIBERATIVISMO-A-POLITICA-2-0-Ronald-S-Stresser-Jr>. Acesso em: 01 ago. 2012.

TOP10. Top 10 melhores blogs de moda do Brasil. Disponível em: <http://top10mais.org/top10-melhores-blogs-de-moda-do-brasil/>. Acesso em: 13 ago. 2012.

UTRINE, Marcelo. (Coord.) Twitter: Influenciando Pessoas \& Conquistando o Mercado! Rio de Janeiro: Alta Books, 2009.

Recebido em: 15.08.2012 / Aprovado em: 20.09.2012

REDESG / Revista Direitos Emergentes na Sociedade Global - www.ufsm.br/redesg v. 1, n. 1, jan.jun/2012 